\title{
Sales Call Anxiety: Investigating the Role of Fear in a Selling Situation
}

\author{
G G Rousseau and $L$ Jansingh
}

Department of Industrial Psychology, University of Port Elizabeth

\section{ABSTRACT}

The main objective of this study was to investigate sales call anxiety (SCA) amongst insurance sales staff in Port Elizabeth. The study was based on past research and uses a modified questionnaire developed in previous research. The sample ( $\mathrm{N}=112$ sales persons) was drawn using a simple random sampling technique. Results confirm four dimensions of SCA identified by Verbeke and Bagozzi (2000), namely negative self-evaluation, negative evaluation from clients, physiological symptoms and protective actions. Significant differences in SCA between black and white salespeople were further observed. These findings have important implications for training of salespeople.

JEL J20, J24, J28

\section{INTRODUCTION}

Sales Call Anxiety (SCA) can be defined as a fear of being negatively evaluated and rejected by clients, and is accompanied by urges to avoid contact with clients or, when contact is made, to refrain from interacting effectively and asking for a commitment (Verbeke \& Bagozzi, 2000). Ray (1995) maintains that SCA is prevalent in selling situations and will reach intense levels for up to 40 per cent of salespeople at some point in their careers. Some people take the refusal of their products and services personally while others consider themselves failures if they do not make a sale every time (Clarke \& Randall, 1995). Cognitive theorists (Beck, 1985; Powell \& Enright, 1990) believe that it is not events or problems that cause anxiety but rather the individual's interpretation of these events that may lead to anxiety problems.

Research conducted by Verbeke and Bagozzi (2000) indicates that SCA consists of four dimensions, namely negative self-evaluations, perceived negative evaluations from clients, physiological responses and protective actions. Negative evaluations of one-self may occur during cold calling (canvassing) or closing of a sale. Concerns about past failures, negative images of the self, anticipated sales encounters and exaggerated considerations of what can go 
wrong during the sales encounter, are what bring about these negative expectations of the self. With regard to imagined negative evaluation from clients, Savitsky, Epley and Gilovich (2001) report that socially anxious people commonly exaggerate fears of public failure or social mishaps by failing to consider the wider range of situational factors that tend to moderate onlookers" impressions. Research by Monfries and Kafer (1994) and Clark and Wells (1995) suggest that people, high in social anxiety, tend to set unrealistically high standards for social performance.

The third dimension of SCA, physiological responses, generally include a pounding heart, perspiration on the palms and face, dry mouth or blushing (Rega, 2000). These bodily changes are integral parts of the fight-or-flight system and are the result of the activation of one portion of the autonomic nervous system (Kleinknecht, 1991). Rapee and Lim (1992) have found that socially anxious salespeople tend to overestimate customers' perceptions of them, which leads to amplification of their own physiological symptoms and further increases social anxiety. The final dimension of SCA involves urges to perform protective actions such as avoiding eye contact, speaking quickly and fiddling with the hands (Verbeke \& Bagozzi, 2000). Extreme protective behaviour such as withdrawal from contact or avoidance of future contact during a sales encounter are usually regarded as dysfunctional.

\section{Antecedents of Sales Call Anxiety}

Although the focus of the present study is on situational aspects of SCA experienced during cold calling and closing of a sale, attention should also be given to antecedents of social anxiety provoking cues, functioning within these settings. One such source of anxiety, arising during cold calling, is when salespeople must initiate contacts with prospects who are of a higher social status. Differences in expectations between the client and salesperson may arise as well as uncertainty regarding respect to be shown.

Another source of anxiety in cold calling situations is the reaction salespeople have to meeting new clients. Without prior knowledge of the needs, style and other characteristics of the prospect, the salesperson is asked to face a set of unknowns. These unknowns may severely influence the pressure to create a favourable impression during the initial encounter, adding tremendously to the level of anxiety experienced by the salesperson. A third source of anxiety which may arise during cold calling is when salespeople have to meet a client from a different culture. In this case, anxiety may arise due to unfamiliarity with the clients' culture and therefore limited knowledge regarding his or her needs and wants. Body language and gestures during the sales encounter may also cause misunderstandings, adding to stress. 
Beatty (1998) states that situational factors such as status, dissimilarity and perceived novelty of an audience or customer, contribute greatly to anxiety levels experienced by the person responsible for the presentation or sale. For closing, the strongest source of anxiety is the anticipation of asking for a commitment and being rejected. Verbeke and Bagozzi (2000) suggest that anticipatory anxiety can lead to cycles of approach-avoidance, procrastination and strong apprehension. Another source of anxiety is the thought of admitting failure to a superior and explaining why the failure occurred. Goodwin, Mayo and Hill (1997) found that when salespeople fail, it negatively affects their feelings of self-esteem.

Experiencing some anxiety however, is part of everyday life and therefore part of being human (Leaman, 1992). When anxiety levels reach heights that are disruptive, though, a person's performance will be negatively influenced leading to emotional disturbance and inability to cope. A further consequence of social anxiety in interpersonal communication, is failure in attention, resulting in a breakdown in communication and lowered performance.

Results obtained from Verbeke and Bagozzi's (2000) study indicated that SCA, which is believed to occur automatically and unconsciously, differed between cold calling and closing of a sale for negative self-evaluations and imagined negative reactions from clients. Anxiety-provoking cues had larger effects on negative self-evaluations and imagined negative evaluations from customers for closing of a sale than for cold calling. In contrast, SCA was invariant across the two types of selling situations when physiological responses and protective actions were considered. These findings suggest similar physiological responses and protective actions, as a function of anxiety provoking cues during cold calling and closing.

The main objective of the present study was to investigate sales call anxiety amongst insurance sales staff in Port Elizabeth. The study was based on research carried out by Verbeke and Bagozzi (2000). The following hypotheses formulated by these researchers were adopted for testing on a multicultural sample:

H1 Sales call anxiety comprises four dimensions: negative self-evaluations, perceived negative evaluation from clients, imagined physiological symptoms and urges to perform protective actions.

H2 Salespeople undergo SCA as a matter of degree that ranges from low to high levels of intensity. Two common contexts in which salespeople face SCA are cold calling and closing the sale. 
H3 Sales call anxiety will be provoked to the extent that salespeople are sensitive to difficulties in dealing with new customers, higher status customers, and customers with different cultures than their own, (three/two facets of cold calling).

H4 Sales call anxiety will be provoked to the extent that salespeople are sensitive to difficulties associated with asking for a commitment and discussing their performance in this regard with their superiors, (three/two facets of closing sales).

\section{METHOD}

A questionnaire was constructed based on items used in a previous study (Verbeke \& Bagozzi, 2000) and was further modified for application in South Africa. All items used in the questionnaire related to the four dimensions of SCA. The last ten items in the questionnaire focused on the degree to which salespeople experienced SCA based on anxiety-provoking cues during cold calling and closing of a sale. A five-point verbal anchored rating scale, suitable for application in developing countries as suggested by Malhotra (1999), was used in the study. The question-naire consisted of 30 items and concluded with measures of several demographic variables.

\section{Sampling Procedure}

A simple random sample $(\mathrm{N}=112)$ was drawn from insurance salespeople employed at various insurance companies in Port Elizabeth. The sampling frame included all insurance salespeople employed at these companies. A total of 177 questionnaires were e-mailed to insurance salespeople of which 112 useable questionnaires were retumed. Questionnaires were self-administered. Each respondent who received a questionnaire was contacted telephonically beforehand, informing him/her of its arrival.

\section{Data Analysis}

The statistical package SPSS was used to perform exploratory factor analyses on the 30 items in the questionnaire. The method of principal component analyses was used with oblimin rotation. A separate factor analysis was performed for each dimension of SCA as well as for the scale measuring the effect of anxiety provoking cues on SCA. Results are summarized in Table 1(a) and (b). 
Table 1(a) Oblique rotated factor analysis matrix for the four dimensions of SCA

\begin{tabular}{|c|c|c|}
\hline Criterion & $\begin{array}{l}\text { Factor } 1 \\
\text { Cold Calling }\end{array}$ & $\begin{array}{r}\text { Factor } 2 \\
\text { Closing }\end{array}$ \\
\hline \multicolumn{3}{|l|}{ Dimension One: Negative Self-Evaluation } \\
\hline 1. I hope I can listen carefully to what the client says. & 0.825 & \\
\hline 2. I hope I will not fumble for words. & 0.856 & \\
\hline 3. I hope I will not give in to the client. & 0.782 & \\
\hline 11. I hope this conversation will not fail. & & 0.771 \\
\hline $\begin{array}{l}\text { 12. I hope it will not turn out that insurance agents from other firms will be } \\
\text { able to convince the client better than I will. }\end{array}$ & & 0.604 \\
\hline 13. I hope that I will not come across as an unfriendly person to the client. & & 0.906 \\
\hline Percentage of total variance explained for dimension one & $51 \%$ & $70 \%$ \\
\hline Cronbach's Coefficient Alpha for dimension one & 0.80 & 0.73 \\
\hline \multicolumn{3}{|l|}{ Dimension Two: Negative Evaluations from Clients } \\
\hline 4. The client will think that I have doubts about what I am selling. & 0.747 & \\
\hline 5. The client does not like me. & 0.933 & \\
\hline $\begin{array}{l}\text { 6. I think that the client will tell other people that I am not a competent } \\
\text { person. }\end{array}$ & 0.889 & \\
\hline 14. The client will think that I am not professional. & & 0.713 \\
\hline $\begin{array}{l}\text { 15. The client will think that agents from other insurance firms are better } \\
\text { salespersons than me. }\end{array}$ & & 0.881 \\
\hline 16. I think that the client will never do business with me again. & & 0.841 \\
\hline Percentage of total variance explained for dimension two & $56 \%$ & $76 \%$ \\
\hline Cronbach's Coefficient Alpha for dimension two & 0.85 & 0.79 \\
\hline
\end{tabular}




\begin{tabular}{|c|c|c|}
\hline Criterion & $\begin{array}{l}\text { Factor } 1 \text { Cold } \\
\text { calling }\end{array}$ & $\begin{array}{l}\text { Factor } 2 \\
\text { Closing }\end{array}$ \\
\hline \multicolumn{3}{|l|}{ Dimension Three: Imagined Physiological Symptoms } \\
\hline 7. I am feeling nervous. & & 0.743 \\
\hline 8. I can't look the client in his eyes. & & 0.565 \\
\hline 17. I am saying too much. & & 0.566 \\
\hline 18. My hands are trembling. & & 0.700 \\
\hline Percentage of total variance explained for dimension three & \multicolumn{2}{|c|}{$42 \%$} \\
\hline Cronbach's Coefficient Alpha for dimension three & \multicolumn{2}{|c|}{0.52} \\
\hline \multicolumn{3}{|l|}{ Dimension Four: Urges to Perform Protective Actions } \\
\hline 9. I cannot talk very persuasively to the client. & 0.839 & \\
\hline 10. I dare not argue with the client. & 0.725 & \\
\hline 19. I must avoid direct questions like "Please will you sign here?" & & 0.736 \\
\hline $\begin{array}{l}\text { 20. I will inform the client that he/she does not have to decide to take out } \\
\text { an insurance policy now, and that he/she may think it over }\end{array}$ & & 0.811 \\
\hline हुำ & & \\
\hline $\begin{array}{l}\text { Percentage of total variance explained for dimension four } \\
\text { Cronbach's Coefficient Alpha for dimension four }\end{array}$ & $\begin{array}{l}36 \% \\
0.46\end{array}$ & $\begin{array}{l}66 \% \\
0.34 \\
\end{array}$ \\
\hline
\end{tabular}

Sample size $N=112$ 
Table 1(b) Oblique rotated factor analysis matrix for anxiety-provoking cues

\begin{tabular}{|c|c|c|}
\hline Criterion & $\begin{array}{c}\text { Factor } 1 \\
\text { Cold Calling }\end{array}$ & $\begin{array}{l}\text { Factor } 2 \\
\text { Closing }\end{array}$ \\
\hline $\begin{array}{l}\text { Anxiety-Provoking Cues } \\
\text { 21. I meet with a client who has a higher social status than myself. }\end{array}$ & 0.760 & \\
\hline 22. I talk to a client who has a higher income than myself. & 0.757 & \\
\hline 23. I prepare for a sales conversation with an unknown prospect. & 0.754 & \\
\hline $\begin{array}{l}\text { 24. Unexpectedly, I have to meet an unknown prospect because my } \\
\text { colleague is unable to do so. }\end{array}$ & 0.627 & \\
\hline 25. I meet with a client whose culture is different to mine. & 0.750 & \\
\hline 26. I meet with a client whose home language is different to mine. & 0.644 & \\
\hline 27. I have to meet with my manager to talk about my sales results. & & 0.682 \\
\hline $\begin{array}{l}\text { 28. I have to discuss my sales results with my manager, and it appears I did } \\
\text { not achieve my sales goals. }\end{array}$ & & 0.772 \\
\hline $\begin{array}{l}\text { 29. The client shows me the offer from a competitor, and I have to respond } \\
\text { to this. }\end{array}$ & & 0.877 \\
\hline 30. I ask the client whether he/she will sign the insurance policy. & & 0.696 \\
\hline Percentage of total variance explained for anxiety-provoking cues & $43 \%$ & $57 \%$ \\
\hline Cronbach's Coefficient Alpha for anxiety-provoking cues & 0.83 & 0.78 \\
\hline
\end{tabular}

Sample size $\mathrm{N}=112$ 
Table 2 Descriptive statistics and correlations for cold calling and closing a sale

\begin{tabular}{|c|c|c|c|c|c|c|c|c|c|c|c|c|c|}
\hline \multicolumn{8}{|c|}{ Cold calling } & \multicolumn{6}{|c|}{ Closing of sale } \\
\hline \multirow{2}{*}{$\begin{array}{c}\text { Dimensions } \\
\text { of SCA }\end{array}$} & \multirow{2}{*}{$\mathbf{N}$} & \multirow{2}{*}{ Mean } & \multirow{2}{*}{ SD } & \multicolumn{4}{|c|}{ Correlations } & \multirow[t]{2}{*}{ Mean } & \multirow[t]{2}{*}{ SD } & \multicolumn{4}{|c|}{ Correlations } \\
\hline & & & & 1 & 2 & 3 & 4 & & & 1 & 2 & 3 & 4 \\
\hline $\begin{array}{l}\text { I Negative } \\
\text { self- } \\
\text { evaluation }\end{array}$ & 112 & 3.29 & 0.91 & - & $0.290^{* * *}$ & $0.236^{* *}$ & $0.437^{* *}$ & 3.34 & 1.02 & - & $0.290^{* *}$ & 0.32 & 0.135 \\
\hline $\begin{array}{l}2 \text { Perceived } \\
\text { negative } \\
\text { evaluation of } \\
\text { clients }\end{array}$ & 112 & 2.12 & 0.84 & $0.290^{* *}$ & $=$ & $0.392^{* *}$ & $0.304^{* *}$ & 2,00 & 0.74 & $0.290^{* *}$ & - & $0.292^{* *}$ & 0.067 \\
\hline $\begin{array}{l}3 \text { lrnagined } \\
\text { physiological } \\
\text { symptoms }\end{array}$ & 112 & 1.96 & 0.69 & $0.263^{* *}$ & $0.329 * *$ & - & $0.247^{* *}$ & 1.94 & 0.57 & 0.032 & $0.292^{* *}$ & - & 0.052 \\
\hline $\begin{array}{l}4 \text { Urges } \\
\text { perform } \\
\text { protective } \\
\text { actions }\end{array}$ & 112 & 2.53 & 0.84 & $0.437^{* *}$ & $0.304^{* *}$ & $0.247 * *$ & - & 2.85 & 0.84 & 0.135 & 0.067 & 0.052 & - \\
\hline
\end{tabular}

** Correlation is significant at the 0.01 level.

* Correlation is significant at the 0.05 level. 
Descriptive statistics such as the mean, standard deviation and Pearson Product Moment Correlations were calculated by means of SPSS. These statistics are reported in Tables 2, 3 and 4. SPSS was subsequently used to perform analysis of variance (ANOVA) to investigate which of the socio-demographical variables are significantly related to the two factors that have emerged. These results are reported in Table 5.

In order to explain the relationship between dependent and independent variables regression analysis was performed. Eight regressions were nun, one for each dimension of SCA. Three anxiety-provoking cues (dealing with higher status customers, meeting new customers and meeting customers with a different culture than your own) were entered as independent variables for cold calling and two anxiety-provoking cues (asking for commitment and anticipating discussion of performance with a manager) were entered as independent variables for closing sales. Table 6 presents the results for the regression analyses.

\section{RESULTS}

Table 1 (a) and (b) show the results of the factor analyses performed in the study. The factor analysis produced two factors, namely Cold calling and Closing of the sale. Dimensions one, two and four in Table 1(a), namely negative self evaluation, perceived negative evaluations from clients and urges to perform protective actions, each loaded on two factors. The scale measuring dimension three, namely imagined physiological symptoms in Table 1(a), only loaded on one factor. An explanation for the latter is that physiological symptoms reflect reactions that are controlled by the autonomic nervous system and tend to be consistent across different anxiety-provoking cues (i.e. cold calling and closing). The scale measuring anxiety-provoking contextual cues in Table 1(b) also loaded on the above mentioned two factors. The Cronbach's coefficient alphas exceeded the required 0.7 criterion for reliability on three of the five subscales in the tables. On two of the dimensions of SCA, physiological symptoms and protective actions, the alphas are marginally below the norm.

Tables 2 and 3 show descriptive statistics and correlations for the sample. As can be seen from Table 2, highly significant positive correlations exist between all four dimensions of SCA during Cold calling (factor 1). For Closing (factor 2 ), highly significant positive correlations occur between 'negative selfevaluation' and 'perceived negative evaluation from clients' as well as between 'perceived negative evaluation from clients' and 'imagined physiological symptoms'. It should be noted that the mean score is highest for 'negative selfevaluation' during both Cold calling and Closing of a sale. This implies that on 
average, insurance salespeople experience SCA fairly intensively during a sales call, due to their insecurity regarding conveying a positive image of themselves to clients.

Table 3 indicates that there are highly significant positive correlations between the first four anxiety provoking cues of SCA, namely meeting (1) new customers, (2) higher status customers, (3) customers with a different culture to the salesperson and (4) asking the customer for a commitment. Moderate significant positive correlations exist between cues (4), asking the customer for a commitment, and (5) discussing performance with a manager. The highly significant positive correlations observed between the first four cues may be due to their impact on the general sales conversation with a client.

Table 3 Descriptive statistics and correlations for anxiety-provoking cues

\begin{tabular}{|c|c|c|c|c|c|c|c|c|}
\hline & & & & & Correlat & ions & & \\
\hline $\begin{array}{l}\text { Anxiety provoking } \\
\text { cues } \\
\end{array}$ & $\mathbf{N}$ & Mean & S.D. & 1 & 2 & 3 & 4 & 5 \\
\hline New customers & 112 & 2.31 & 0.95 & - & $0.479^{* *}$ & $0.426^{* *}$ & $0.339 * *$ & 0.178 \\
\hline 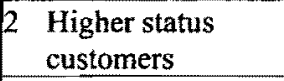 & 112 & 2.56 & 1.02 & $0.479^{* *}$ & - & $0.509 * *$ & $0.343^{* *}$ & 0.164 \\
\hline 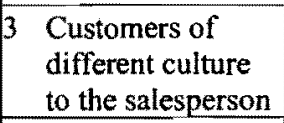 & 112 & 2.23 & 0.99 & $0.426^{* *}$ & $0.509^{* *}$ & - & $0.409 * *$ & 0.165 \\
\hline $\begin{array}{l}4 \text { Asking for } \\
\text { commitment }\end{array}$ & 112 & 2.53 & 1.03 & $0.339 * *$ & $0.343^{* *}$ & $0.409 * *$ & - & $0.226^{*}$ \\
\hline $\begin{array}{l}5 \text { Discussing perfor- } \\
\text { mance with a } \\
\text { manager }\end{array}$ & 112 & 2.62 & 0.92 & 0.178 & 0.164 & 0.165 & $0.226^{*}$ & $=$ \\
\hline
\end{tabular}

Table 4 shows descriptive statistics for the factors grouped according to demographic variables obtained from the sample, as well as those factor score differences that are significant. From the table it can be seen that Coloured males between the ages of 18 and 25 who have less than 2 years' experience in selling insurance, and whose highest level of education is a diploma, scored highest on Cold calling (factor 1). This may be an indication that the younger and less experienced one is at selling insurance, the more anxious one will be during Cold calling. Generalization would not be wise, however, seeing that the number of respondents in this group was very small. 
Table 4 Descriptive statistics by gender, race, age, education, and service

\begin{tabular}{|c|c|c|c|c|c|}
\hline & \multirow[b]{2}{*}{$\mathbf{N}$} & \multirow{2}{*}{$\begin{array}{c}\text { Factor } 1 \\
\text { Mean }\end{array}$} & \multirow[b]{2}{*}{ S.D. } & \multicolumn{2}{|c|}{ Factor 2} \\
\hline & & & & Mean & S.D. \\
\hline \multicolumn{6}{|l|}{ Gender } \\
\hline Male & 75 & 2.527 & 0.559 & 2.544 & 0.513 \\
\hline Female & 37 & 2.489 & 0.664 & 2.592 & 0.511 \\
\hline \multicolumn{6}{|l|}{ Race } \\
\hline White & 71 & $2.410 \mathrm{a}$ & 0.609 & $2.485 \mathrm{c}$ & 0.550 \\
\hline Black & 30 & $2.717 \mathrm{~b}$ & 0.453 & $2.757 \mathrm{~d}$ & 0.348 \\
\hline Coloured & 9 & 2.767 & 0.707 & 2.611 & 0.491 \\
\hline Asian & 2 & 2.050 & 0.212 & 2.050 & 0.495 \\
\hline \multicolumn{6}{|l|}{ Age } \\
\hline $18-25 \mathrm{yrs}$ & 17 & 2.641 & 0.548 & 2.559 & 0.379 \\
\hline $26-35$ & 41 & 2.568 & 0.703 & 2.654 & 0.548 \\
\hline $36-49$ & 41 & 2.378 & 0.505 & 2.446 & 0.503 \\
\hline $50+$ & 13 & 2.608 & 0.499 & 2.623 & 0.546 \\
\hline \multicolumn{6}{|c|}{ Education (highest level) } \\
\hline Matric & 69 & $2.532 \mathrm{~g}$ & 0.516 & 2.610 & 0.462 \\
\hline Diploma & 26 & $2.585 \mathrm{i}$ & 0.686 & 2.542 & 0.617 \\
\hline Degree & 11 & 2.555 & 0.780 & 2.455 & 0.557 \\
\hline Post-graduate degree & 6 & $1.933 \mathrm{~h}$ & 0.413 & 2.250 & 0.446 \\
\hline \multicolumn{6}{|c|}{ Years of service as an insurance agent } \\
\hline $0-2$ yrs & 31 & 2.632 & 0.508 & 2.655 & 0.381 \\
\hline $3-5$ & 27 & 2.611 & 0.644 & $2.741 \mathrm{e}$ & 0.448 \\
\hline $6-19$ & 50 & 2.420 & 0.610 & $2.416 \mathrm{f}$ & 0.575 \\
\hline $20+$ & 4 & 2.125 & 0.411 & 2.400 & 0.548 \\
\hline Total sample & 112 & 2.475 & 0.557 & 2.523 & 0.495 \\
\hline \multicolumn{6}{|c|}{ Significant differences * / Observable differences " } \\
\hline \multicolumn{6}{|c|}{\begin{tabular}{|l|l|l|} 
Gender & & \\
\end{tabular}} \\
\hline Race & $a b^{*}$ & $c d^{*}$ & & & \\
\hline \multicolumn{6}{|l|}{ Age } \\
\hline Education & g h" & i h" & & & \\
\hline $\begin{array}{l}\text { Years of service as an } \\
\text { insurance agent }\end{array}$ & ef * & & & & \\
\hline
\end{tabular}


With regard to Closing of the sale (factor 2), Table 4 suggests that black females between 26 and 35 who have matriculated and have 3 to 5 years' experience in selling insurance, scored highest. As with factor 1 , it can be assumed that these results are due to the fact that salespeople experience high levels of anxiety when they are younger and less experienced in insurance selling. The reason for black respondents experiencing higher levels of anxiety during Closing may also be due to their having less experience when compared to white respondents. This may be a result of black people being previously disadvantaged in terms of access to jobs of such nature.

Table 5 Analysis of variance to determine relationships between sociodemographic variables and factors

\begin{tabular}{|l|c|c|c|c|c|}
\hline & \multicolumn{3}{|c|}{ Cold calling } & \multicolumn{2}{c|}{ Closing } \\
\hline Gender & $\mathbf{f}$ & $\mathbf{F}$ & $\mathbf{p}$ & $\mathbf{F}$ & $\mathbf{p}$ \\
Race & 1 & 0.980 & 0.755 & 0.216 & 0.643 \\
Age & 3 & 3.008 & $0.033^{*}$ & 2.826 & $0.042^{*}$ \\
Education & 3 & 1.210 & 0.310 & 1.209 & 0.310 \\
Years of service as an & 3 & 2.145 & $0.099^{\prime \prime}$ & 1.129 & 0.341 \\
insurance agent & & 1.676 & 0.176 & 3.105 & $0.030^{*}$ \\
\hline
\end{tabular}

$\mathrm{N}=112$

Significant correlation $\quad{ }^{*} \mathrm{p}<0.05$

Reportable correlation $\quad p<0.10$

Table 5 shows which of the socio-demographic variables are significantly related to the identified factors. From the table it can be seen that race is significantly related to Cold calling (factor 1) and Closing (factor 2). 'Years of service as an insurance agent' is significantly related to Closing (factor 2). Table 5 further suggests that a reportable correlation exists between educational levels and Cold calling (factor 1). Table 4 shows significant differences between white and black respondents in terms of Cold calling and Closing. Table 4 further indicates that respondents with 3 to 5 years' of service as an insurance agent scored significantly higher than those with 6 to 9 years service on Closing. Table 4 also shows that respondents with a matric or a diploma scored reportedly higher on SCA during Cold calling than those with a postgraduate degree. These inferences suggest that race, sales experience and education are major role players in SCA. 


\section{Table 6 Regression analyses}

\begin{tabular}{|c|c|c|c|c|c|c|c|}
\hline \multirow[b]{3}{*}{$\begin{array}{l}\text { Dependent } \\
\text { variables }\end{array}$} & \multicolumn{4}{|c|}{ Cold calling } & \multicolumn{3}{|c|}{ Closing } \\
\hline & \multicolumn{7}{|c|}{ Independent variables: anxiety-provoking cues } \\
\hline & $\begin{array}{c}\text { Dealing } \\
\text { with higher } \\
\text { status } \\
\text { customers }\end{array}$ & $\begin{array}{c}\text { Meeting } \\
\text { new } \\
\text { people }\end{array}$ & $\begin{array}{c}\text { Meeting } \\
\text { customers of } \\
\text { a different } \\
\text { culture }\end{array}$ & $\mathbf{R}^{2}$ & $\begin{array}{c}\text { Asking for } \\
\text { a commit- } \\
\text { ment }\end{array}$ & $\begin{array}{c}\text { Discussing } \\
\text { perfor- } \\
\text { mance with } \\
\text { manager }\end{array}$ & $\mathbf{R}^{2}$ \\
\hline $\begin{array}{l}\text { Negative } \\
\text { self- } \\
\text { evaluation }\end{array}$ & $0.257^{*}$ & 0.120 & $0.287^{* *}$ & 0.14 & 0.002 & $0.746 * * *$ & 0.55 \\
\hline $\begin{array}{l}\text { Negative } \\
\text { evaluation } \\
\text { from clients } \\
\text { Physio- }\end{array}$ & $0.279^{*}$ & 0.115 & 0.118 & 0.06 & $0.232 * *$ & $0.405 * * *$ & 0.25 \\
\hline $\begin{array}{l}\text { Symptoms } \\
\text { Protective } \\
\text { actions }\end{array}$ & $\begin{array}{l}0.268^{*} * \\
0.254^{*}\end{array}$ & $\begin{array}{l}0.166 \\
0.070\end{array}$ & $\begin{array}{l}0.107 \\
0.113 \\
\end{array}$ & $\begin{array}{l}0.17 \\
0.06 \\
\end{array}$ & $\begin{array}{l}0.337^{* * *} \\
0.115\end{array}$ & $\begin{array}{l}0.034 \\
0.082 \\
\end{array}$ & $\begin{array}{l}0.10 \\
0.01 \\
\end{array}$ \\
\hline
\end{tabular}

*** Correlation is significant at the 0.001 level

** Correlation is significant at the 0.01 level

* Correlation is significant at the 0.05 level

Table 6 summarizes the findings of the regression analyses. The reported $R^{2}$ values in Table 6 indicate extremely low to moderately high proportions of variance in SCA. It was found that anxiety-provoking cues relating to Closing (factor 2) explained the highest proportion of variance (55 per cent) in dimension one, namely negative self-evaluation. Anxiety-provoking cues relating to Cold calling (factor 1) explained the highest proportion of variance ( 17 per cent) in dimension three, namely imagined physiological symptoms.

The anxiety-provoking cue 'dealing with higher status customers' was found to signilicantly influence all four dimensions of SCA during Cold calling, with imagined physiological symptoms being affected most. Anxiety provoking cue 'mecting new pcople' was found not to influence any of the dimensions of SCA significantly. This is an interesting finding as one would expect that in meeting customers who are unknown to you, the level of SCA should be influenced positively. Cue three namely meeting customers of a different culture than oneself, significantly influences only one dimension namely 'negative selfevaluation'. 
With regard to Closing the sale 'asking for a commitment' was found to significantly influence dimensions two and three, namely 'negative evaluations from clients' and 'imagined physiological symptoms'. The latter was found to be affected the most by this anxiety-provoking cue. Anxiety-provoking cue 'discussing performance with a manager' was found to significantly influence both 'negative self-evaluation' and 'negative evaluation from clients'. The study conducted by Verbeke and Bagozzi (2000) resulted in the four anxietyprovoking cues, namely dealing with higher status customers, meeting new customers, asking for a commitment and discussing performance with a manager, significantly influenced all four dimensions of SCA. In the present study however, the anxiety provoking cues significantly influenced the dimensions of SCA in certain instances only.

\section{Hypotheses Testing}

With regard to hypothesis one stating that SCA comprises four dimensions, namely negative self-evaluation, perceived negative evaluations from clients, imagined physiological symptoms and urges to perform protective actions, Table 1(a) shows that all items satisfactory loaded to these four dimensions. Table 2 further shows significant positive correlations between all four dimensions relating to cold calling and significant positive correlations between three of the four dimensions relating to closing a sale. Hypothesis one may therefore be accepted.

Hypothesis two, stating that salespeople undergo SCA as a matter of degree, ranging from low to high levels of intensity within two common contexts, cold calling and closing, is upheld. Results of the factor analysis presented in Table 1 revealed two factors, namely cold calling and closing the sale. Furthermore, Table 2 shows that during cold calling and closing the sale, many salespeople experience high levels of SCA, due to negative self-evaluative thoughts during the sale, and experience low levels of SCA, due to imagined physiological symptoms such as shaky hands. Hypothesis two may therefore be accepted.

Hypothesis three stated that SCA will be provoked to the extent that salespeople are sensitive to difficulties in dealing with new customers, higher status customers, and customers with different cultures than their own (three/two facets of cold calling). Observations from Table 1(b) show that items 21 to 26 of the scale that measured difficulties in dealing with new, high status or culturally different customers, were related to cold calling, which is a facet of SCA. Results from Table 6 further show that the anxiety-provoking cues dealing with high status customers and customers of a different culture than one's own, significantly influence certain dimensions of SCA. Although no statistical evidence exists to prove that 'meeting new customers' does provoke 
SCA, the fact that it does relate to SCA will be regarded as sufficient evidence to infer its importance as an anxiety-provoking cue. Hypothesis three may therefore be accepted.

Hypothesis four stated that SCA will be provoked to the extent that salespeople are sensitive to difficulties associated with asking for a commitment and discussing their performance in this regard with their supervisor (three/two aspects of closing sales). Observations from Table 1(b) show that items 27 to 30 relate to closing the sale. These four items refer to the extent that salespeople are sensitive to difficulties associated with asking for a commitment and discussing their performance in this regard with their supervisor. Table 6 indicates that the two anxiety-provoking cues, namely asking for a commitment and discussing performance with a superior, significantly influence certain dimensions of SCA during the closing of a sale. Hypothesis four may therefore be accepted.

\section{CONCLUSION}

The main objective of this study was to investigate sales call anxiety amongst insurance sales staff in Port Elizabeth. Based on previous research, four hypotheses were formulated and tested. The results of the study revealed two factors emerging from factor analyses, performed for items relating to each dimension of SCA, and items relating to anxiety-provoking cues in the questionnaire. The factors were Cold calling and Closing. This finding supports that of a previous study by Verbeke and Bagozzi (2000). Results featured in Table 2 show positive correlations between the four dimensions of SCA during cold calling and closing in some cases. Table 3 also suggests positive correlations between the five anxiety-provoking cues.

On inspection of socio-demographic variables and the factor scores obtained, it could be seen that race was significantly related to both cold calling (factor 1 ) and closing (factor 2) while years of experience in selling insurance was significantly related to closing the sale. These findings suggest that significant differences in terms of anxiety experienced, exist between black and white salespeople during the sale, and that the less experienced one is at selling insurance, the more anxiety will be experienced during closing of the sale. Results of the regression analyses, performed for each dimension of SCA, revealed that anxiety-provoking cues create low to moderately high amounts of variance in $\mathrm{SCA}$.

In summary, the findings of this study demonstrate that SCA does in fact consist of four dimensions: negative self-evaluations, perceived negative evaluations 
from clients, imagined physiological symptoms and protective actions. The experience of SCA differs between cold calling and closing the sale, and anxiety-provoking cues have a moderate effect on the level of anxiety experienced during a sale. All four the hypotheses could therefore be upheld. Despite the limitations of a relatively small sample that is not representative of all the population groups, and some scales not meeting the required 0,70 criterion for reliability, the results of the study do confirm significant correlations between the constructs as predicted by Verbeke and Bagozzi (2000). Therefore nomological validity of the study is suggested.

Follow-up research in South Africa is, however, needed to provide guidelines for sales managers in assisting salespersons to deal with sales call anxiety. Sales managers need to learn to detect signs of SCA in their salespeople. According to Miles and Snow (1978), sales managers may notice the effects of anxiety when sales force strategies change or when salespeople change accounts. Training and professional treatment can go a long way in preventing negative self-evaluation, imagined negative evaluation from clients, imagined physiological symptoms and urges to perform protective actions. One of the best ways to offset the effects of these anxiety provoking cues is to alert trainees of the existence of SCA and to teach them how to control it in role playing sessions and behaviour modification.

\section{REFERENCES}

1 BEATTY, M. (1988) "Situational and Predispositional Correlates of Public Speaking Anxiety", Communication Education, 37 (1): 28-39.

2 BECK, A.T. (1976) Cognitive Therapy and the Emotional Disorders, New York: International University Press.

3 CLARK, D.M. \& WELLS, A. (1995) "A Cognitive Model of Social Phobia", In R.G. Heimberg, M. Liebowitz, D.A. Hope, \& F. Schneier (eds.) Social Phobia: Diagnosis, Assessment and Treatment: 69-93, New York: Guilford Press.

4 CLARKE, R.D. \& RANDALL, I. (1999) "Cold Calls, Cold Feet", Black Enterprise, 29 (8): 125-27.

5 GOODWIN, C., MAYO, M. \& HILL, R.P. (1997) "Sales Response to Loss of a Major Account: A Qualitative Analysis", Journal of Business Research, 40: 167-80.

6 KLENNKNECHT, R.A. (1991) Mastering Anxiety: The Nature and Treatment of Anxious Conditions, New York: Plenum Press.

7 LEAMAN, T.L. (1992) Healing the Anxiety Diseases, New York: Plenum Press. 
8 MALHOTRA, N.K. (1999) Marketing Research: An Applied Orientation, $\left(3^{\text {rd }}\right.$ ed.) New Jersey: Prentice Hall.

9 MILES, R.E. \& SNOW, C.C. (1978) Organizational Strategy, Structure, and Process, New York: McGraw-Hill.

10 MONFRIES, M.M. \& KAFER, N.F. (1994) "Private Self-Consciousness and Fear of Negative Evaluation", Journal of Psychology, 128 (4): 447 54.

11 POWELL, T.J. \& ENRIGHT, S.J. (1990) Anxiety and Stress Management, London: Routledge.

12 RAPEE, R.M. \& LIM, L. (1992) "Discrepancy Between Self- and Observer Ratings of Performance in Social Phobics", Journal of Abnormal Psychology, 101: 728-31.

13 RAY, D. (1995) "Confront Call Reluctance", Personal Selling Power, (September): 46-51.

14 REGA, M.E. (2000) "Call and Presentation Reluctance", American Salesman, 45 (3): 10-14.

15 SAVITSKY, K., EPLEY, N. \& GILOVICH, T. (2001) "Do Others Judge us as Harshly as We Think? Overestimating the Impact of Our Failures, Shortcomings and Mishaps", Journal of Personality \& Social Psychology, 81 (1): 44-56.

16 VERBEKE, W. \& BAGOZZI, R.P. (2000) Sales Call Anxiety: Exploring What It Means When Fear Rules a Sales Encounter. Journal of Marketing, 64 (July), 88-101. 